www.jmscr.igmpublication.org

Index Copernicus Value: 79.54

ISSN (e)-2347-176x ISSN (p) 2455-0450

crossrefDOI: https://dx.doi.org/10.18535/jmscr/v7i2.13

\title{
Comparative study of Endometrial Thickness with Histopathological pattern of Endmetrium in Postmenopausal Bleeding
}

\author{
Authors \\ Dr Shailesh Kumar Pankaj ${ }^{1}$, Dr (Prof.) Lata Shukla Dwivedy ${ }^{2}$, \\ Dr Om Prakash Dwivedy ${ }^{3}$ \\ ${ }^{1}$ Tutor, Dept. of Pathology N.M.C.H., Patna \\ ${ }^{2}$ Dept. of Obst \& Gynae \\ ${ }^{3}$ Associate Professor, Dept. of Pathology N.M.C.H., Patna \\ Corresponding Author \\ Dr (Prof.) Lata Shukla Dwivedy
}

\begin{abstract}
Aims \& Objective: The aim of the present study was to study endometrial thickness by transvaginalsonography and correlate it with the Histopathological pattern in case of Post menopausal bleeding.

Material \& Methods: The present prospective cohort study was conduct in the Dept of Obst \& Gynae\& Pathology of Nalanda Medical College \& Hospital, Patna from July 2015 to June 2017.

Results: Out of 120 patients, majority 46 (38.33) had atrophic endometrium, endometrial hyperplasia in 28 (23.66\%) out of which 22 had simple hyperplasia and 6 had atypical hyperplasia, endometrial polyp in 4 (3.33\%) and two cases was confirmed as endometrial carcinoma on Histopathological examination. Majority of patients (40\%) had ET $<4 \mathrm{~mm}$. and 12 patient had ET $>10 \mathrm{~mm}$.

In Patient with normal and atrophic histopathology, majority had ET $<4 \mathrm{~mm}$ and those with hyperplasia had ET>4 and with polyp ET>6mm. No case of polyp and endometrial cancer was diagnosed at ET <6mm. Conclusion: Role of endometrial thickness cannot be ignored for detecting patients at high risk especially with co-morbid conditions. Histopathological evaluation is mandatory for ruling out malignancy is selected cases of post menopausal bleeding (PMB).
\end{abstract}

Keywords: Postmenopausal bleeding (PMB), TVS (Transvaginalsonography), ET (Endometrial thickness), Histopathological pattern of endometrium.

\section{Introduction}

Permanent Cessation of menstruation with loss of ovarian follicular activity is called menopaus ${ }^{1}$. Bleeding that occurs 12 months after the last menstrual period is labeled as postmenopausal bleeding (PMB). The incidence of menopausal bleeding is around 3\% and require prompt and thorough evaluation. The main aim was to rule out endometrial pathology (Carcinoma and atypical hyperplasia). The Screening modalities for endometrial cancer include, TVS, saline infusion sonography, 3-D color Doppler, Ultrasound, hysteroscopy and endometrial biopsy.

In the present study, non-invasive TVS, and endometrial biopsy by minimally invasive technique endometrial aspiration and dilatation and curettage has been used for evaluation of endometrial pathology in Patient with post menopausal bleeding. 


\section{Material \& Method}

The present prospective cohort study was conducted in the department of Obst\&Gynae and Pathology in Nalanda Medical College \& Hospital, from July 2015 to June 2017. A total of 120 cases were included in this study, who presented with postmenopousal bleeding or spotting. The study was approved by the institutional ethical and research review board.

Inclusion Criteria: Pt. with Post menopausal bleeding or spotting.

\section{Exclusion Criteria}

1. Patient with vaginal infection

2. Pre-malignant and Malignant lesions of vagina vulva and cervix.

3. Cervical and endocervical pathology.

4. Bleeding disorders.

5. Adnexal masses.

6. Patient on hormonal therapy.

After history, detailed clinical examination and routine investigation all patients were subjected to Pap smear and endometrial biopsy by D\&C for Histopathological examination.

This was preceded by TVS, character that were on TVS included.

7. Endometrial thickness in $\mathrm{mm}$.

8. Echogenicity of endometrium.

9. Uterine size.

10. Uterine cavity, any fluid in, growth/polyp.

11. Cervical canal.

12. Myometrium.

13. Bilateral Adnexa

Endometrium and cavity were considered normal if TVS showed a hyperechoic line in midline of the uterus with a homogenous endometrial lining with distinct margins.

Endometrial cancer was suspected in presence of heterogenous endometrium with irregular interface between endometrium and myometrium with or without fluid collection. In invasive cancer subendometrial halo is lost. The findings were noted and Patients were scheduled for D\&C/endometrial aspiration after pre-anesthetic checkup. The Histopathological pattern was analysed. All the above data were compiled and statistically analysed.

\section{Result}

120 patients presenting with a post-menopausal bleeding in OPD and labour room, after apply both inclusion and exclusion criteria were enrolled in present study.

Majority of patients (40\%) had ET $<4 \mathrm{~mm} .12$ patient had ET $>10 \mathrm{~mm}$. Majority $(38.33 \%)$ of patients had atrophic endometrium and normal endometrium (10\%) on Histopathological examination. Endometrial hyperplasia was detected in 28 (23.33\%) out of which 22 had simple hyperplasia and 6 had atypical hyperplesia. Endometrial malignancy was detected in 16 (13.13\%) patients. Out of 16 cases of endometrial malignancy, two cases were confirmed as endometrial adenocarcinoma on Histopathological after polypectomy/ hysterectomy. In Patient with normal and atrophic histopathology, majority had ET $<4 \mathrm{~mm}$ and those with hyperplasia had ET $>4 \mathrm{~mm}$ and with polyp ET $>6 \mathrm{~mm}$. No case of polyp and endometrial cancer was diagnosed at ET $<6 \mathrm{~mm}$.

Table:1 Distribution of cases according to endometrial thickness on TVS $(n=120)$.

\begin{tabular}{|c|c|c|}
\hline 1. $\quad$ ET $(\mathrm{mm})$ & No. of Cases & Percentage (\%) \\
\hline$>4$ & 48 & 40 \\
\hline 4.1-6 & 26 & 21.67 \\
\hline $6.1-8$ & 16 & 13.33 \\
\hline 8.1-10 & 18 & 15 \\
\hline$>10$ & 12 & 10 \\
\hline Total & 120 & 100 \\
\hline
\end{tabular}

Table: 2 Distribution of cases according to Histopathological pattern $(n=120)$

\begin{tabular}{|l|c|c|}
\hline \multicolumn{1}{|c|}{ 1. Histopathology } & $\begin{array}{c}\text { No. of } \\
\text { cases }\end{array}$ & $\begin{array}{c}\text { Percentage } \\
(\boldsymbol{\%})\end{array}$ \\
\hline Normal & 12 & 10 \\
\hline Atrophic & 46 & 38.33 \\
\hline Disordered & 14 & 11.67 \\
\hline Endometrial polyp & 4 & 3.33 \\
\hline Hyperplasia simple & 22 & 18.33 \\
\hline Hyperplasia atypical & 6 & 5.0 \\
\hline Malignancy & 16 & 13.33 \\
\hline Total & $\mathbf{1 2 0}$ & $\mathbf{1 0 0}$ \\
\hline
\end{tabular}


Table: 3 Comparison of endometrial thickness with Histopathological pattern $(n=120)$

\begin{tabular}{|l|c|c|c|c|c|c|}
\hline Histopathology & No. of cases & \multicolumn{5}{|c|}{ Endometrial thickness on TVS (in mm) } \\
\hline & & $\mathbf{4}$ & $\mathbf{4 . 1 - 6}$ & $\mathbf{6 . 1 - 8}$ & $\mathbf{8 . 1 - 1 0}$ & $>\mathbf{1 0 . 1}$ \\
\hline Normal & 12 & 10 & 0 & 2 & 0 & 0 \\
\hline Atrophic & 46 & 34 & 10 & 2 & 0 & 0 \\
\hline Disordered & 14 & 2 & 8 & 4 & 0 & 0 \\
\hline Endometrial polyp & 4 & 0 & 0 & 2 & 2 & 0 \\
\hline Hyperplasia & 28 & 6 & 8 & 6 & 6 & 2 \\
\hline Malignancy & 16 & 0 & 0 & 2 & 2 & 12 \\
\hline
\end{tabular}

\section{Discussion}

Present study was undertaken to evaluate how best a patient with PMB can be investigated by noninvasive or minimally invasive techniques. In the present study, benign pathology (normal, atrophic, Polyp, myoma) was diagnosed in $51.66 \%$ out of which majority had atrophic endometrium. Endometrial malignancy was detected in 16 $(13.33 \%)$ cases, 2 cases was confirmed as endometrial adenocarcinoam on Histopathological examination after hysterectomy.

Similar incidences have been reported in studies of Karlssonet $\mathrm{al}^{2}$, \& Kaur et $\mathrm{al}^{3}$. Thus all patients with PMB need Preliminary evaluation by TVS for ET and endometrial sampling to rule out premalignant and malignant pathology as early as possible.

Conduction of transvaginalsonography to the diagnostic armamentarium of gynecologist has definitely been beneficial in early diagnosis and treatment in patients with PMB. Endometrial biopsy can help further evaluation and treatment in patients with $\mathrm{PMB}$.

\section{Conclusion}

Evaluation of PMB at the earliest is essential for diagnosing endometrial status for early intervention. Role of endometrial thickness cannot be undermined for detecting patients at high risk especially with co-morbid conditions. Histopathological evaluation is mandatory for ruling out malignancy in PMB. TVS can be considered as a first line modality in the management of cases of PMB.

\section{References}

1. Evaluation and management of postmenopausal bleeding. Indian Menopause Society. Guideline Number 4: August 2010.

2. Karlsson B, Granberg S, Wikland M, et al. Transvaginalultrasonography of endometrium in women with postmenopausal bleeding -a Nordic multicenter study. Am J Obstet Gynecol. 1995; 172 (1488-149):4.

3. Kaur M, Singh R, Sharma $M$. Endovaginalsonographic evaluation of postmenopausal uterine bleeding. J ClinDiagn Res. 2010, 4(2): 2175-82.

4. Gerber B, Krause A, Kuelz T, et al. Rating of transvaginalsonography in the evaluation of postmenopausal bleeding ZentralblGynakol. 1999;121(3):143-8. 